\title{
BALUARTES, MOSQUETES Y RECLUTAS: CUESTIONES EN TORNO A LA HISTORIOGRAFÍA MILITAR MODERNISTA (SIGLOS XVI-XVIII)
}

POR

\author{
LUIS SALAS ALMELA
}

\section{RESUMEN - ABSTRACT}

Dentro del campo de la historiografía militar —en un sentido amplio- de los siglos XVI al XVIII, se han seleccionado algunas cuestiones que por su influencia e innovación conceptual han supuesto mayores aportaciones a la comprensión general del período moderno en su conjunto. A partir de ellas, se ha tratado de valorar los principales logros y los escollos más enconados que los historiadores de la especialidad han ido ofreciendo y encontrando en las últimas décadas. Las escuelas historiográficas de lo militar que, en función precisamente de su desarrollo, han encontrado mayor cabida en estas páginas son la británica y, en menor medida, la francesa. Ambas, por otro lado, son las que más han influido en los historiadores españoles. Como conclusión, el autor sugiere que las principales aportaciones metodológicas y conceptuales de la historiografía militar modernista se han producido precisamente en el momento en el que se ha abandonado la pretensión de hacer de lo específicamente militar el factor clave en el desarrollo histórico de las sociedades europeas. La justa ubicación dentro de la ciencia histórica es la que, paradójicamente, más está favoreciendo el desarrollo de la historia militar.

Abstract: We have selected some questions of military historiography from XVIth to XVIIIth century according to their influence on the global comprehension of the early modern history. From this subject we have evaluated dificulties and goals in the last decades. We have specially paid attention to the British and French historiographycal traditions because of their development and significance on the Spanish way of facing the military history. In conclution, we suggest that the main methodological and conceptual contributions of the special field that concerns us in this article have to be related to the last years. This matched with the moment in which these historians have changed their attempt to focus the most important changes in the early modern period from their specialism. Best results have been achieved when they have recognized a more modest status for the military history.

\section{PALABRAS CLAVE - KEY WORDS}

Historia Moderna. Historia militar. Historiografía. Desarrollo del Estado. Revolución Militar.

Early Modern History. Military History. Historiography. Nation Building. Military Revolution.

\section{INTRODUCCIÓN}

La guerra, como objeto de estudio histórico, es uno de los argumentos más clásicos de los profesionales de esta eterna aspirante a ciencia que es la Historia. Y como tal, su tradición, la producción historiográfica propiamente dicha, es enorme. En cambio, pese a todo ese bagaje, su inserción en el mundo académico universitario en el siglo que acabamos de abandonar ha sido más bien compleja y de difícil recorrido, manteniendo a veces unas relaciones bien poco 
cordiales con otras especializaciones del saber histórico ${ }^{1}$. Las causas de esta situación no son, ni mucho menos, el objeto de estudio de este artículo. No obstante, tampoco van a ser totalmente ajenas a él. De lo que aquí vamos a tratar es de ciertos aspectos teóricos y metodológicos que han hecho peculiar a esta rama de la Historia y que acaso también hayan contribuido a ese distanciamiento que, bueno es que se diga desde el principio, parece que va quedando superado a la vista, tanto de las nuevas aportaciones de este campo, como a la proliferación de centros de estudio específicos de lo militar en las estructuras universitarias.

En efecto, la historia militar quedó desde los mismos inicios del siglo XX poco a poco marginada de las principales líneas de investigación universitarias, a medida que la sociedad sustituía a los individuos como elementos esenciales del análisis histórico. Esto fue así, al menos en parte, debido a que la historia militar estaba indisolublemente asociada a una forma de hacer historia política de los acontecimientos contra la que se alzaron las voces más renovadoras de la historiografía. En especial, el impulso de la escuela de los Annales denostó la forma de abordar los procesos históricos desde la perspectiva de lo que podríamos llamar las personalidades del poder y sus actuaciones relacionadas, de entre las cuales la guerra era expresión máxima según aquella historiografía episódica (événementielle). Los historiadores de la nueva corriente iniciaron una búsqueda de objetos de estudio que permitiesen hacer una historia desde abajo, desde las bases de la sociedad, lo que implicaba relegar los acontecimientos - muy especialmente las batallas - a la categoría de mera superficie de los profundos movimientos de la historia de las sociedades. El ejemplo máximo en el que inmediatamente pensamos todos es el clásico estudio de Fernand Braudel sobre el Mediterráneo en tiempos de Felipe II, en el que significativamente los acontecimientos aparecen, casi como un epílogo probatorio de lo argumentado, en la tercera parte de la obra ${ }^{2}$.

Por otra parte, la conquista de los puestos directivos de las universidades en las décadas siguientes por los defensores de esta nueva forma de hacer historia marginó, a medida que la vieja guardia iba siendo sustituida, a no pocas ramas del saber histórico ${ }^{3}$. De aquel rechazo inicial, que también afectó a los ámbitos historiográficos en los que las estructuras de poder centrales eran los indiscutibles protagonistas - así las historias del poder, de las relaciones internacionales o de la política en general—, se produjo el casi total abandono de la perspectiva militar por parte de los historiadores académicos. Y decimos académicos porque otros estudiosos del pasado, no profesionales de la historia, no se han visto afectados por este rechazo ni por los debates epistemológicos que lo propiciaron, toda vez que su búsqueda en los archivos ha estado más guiada por la curiosidad erudita que por el método crítico de las ciencias sociales ${ }^{4}$.

Aquella preponderancia excluyente de los temas que, por no entrar en otros debates que nos alejarían de nuestro argumento, podemos agrupar bajo el título de sociales ha venido siendo sorteada con diferente éxito por las diversas ramas del estudio histórico que hemos

1 Como reconocen G. Best en su «Prólogo a la edición inglesa» del libro de J. R. Hale: Guerra y sociedad en la Europa del Renacimiento (1450-1620), Madrid, 1990 [1985]; o C. J. Rogers en la breve introducción del volumen dirigido por él, The military revolution: Readings on the military transformation of early modern Europe, Oxford, 1995, p. 1.

2 Braudel, F.: El Mediterráneo y el mundo mediterráneo en la época de Felipe II, Méjico, 1987 [París, 1949], 2 vols., volumen II, pp. 333-786.

3 Lynn, J. A. señala que tras la Segunda Guerra Mundial en Francia la historia militar fue expulsada («was reject») de las universidades, en Giant of the Grand Siècle. The French Army, 1610-1715, Cambridge, 1997, p. XI.

${ }_{4}^{4}$ En Francia, Robert Vial discutió hace ya algunos años cuál debía ser la relación entre los militares profesionales y la historia del ejército. En su opinión, si bien se debía fomentar el conocimiento del pasado militar de Francia entre sus militares, la investigación debía dejarse en manos de profesionales específicamente formados para ello. Ver «L'Armée Françoise et l'Histoire», en Revue Historique des Armées, 1991 (3), pp. 111-123. En nuestra opinión, si bien es cierto que las ciencias sociales requieren cada vez un mayor grado de dedicación y especialización, es discutible que la historia como saber sea imprescindible para el militar profesional; tampoco creemos que los trabajos de corte erudito elaborados por historiadores militares deben ser sin más desechados. 
mencionado. Sin embargo, la historia militar ha tardado más que otras en asumir las consecuencias que la revolución historiográfica iniciada en la revista dirigida por Henri Berr a

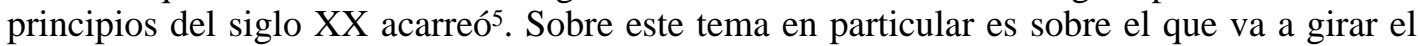
presente artículo, aunque no nos mueva el afán de hacer un seguimiento exhaustivo de esta relación compleja entre ramas del saber historiográfico. Por el contrario, nuestro trabajo va a adoptar la estructura de un ensayo crítico en la creencia de que ésta es la forma que mejor se adapta a la aproximación que aquí pretendemos ${ }^{6}$. Nuestro propósito es el de rastrear las principales aportaciones teóricas y metodológicas que la historia militar en general — vamos a utilizar trabajos de historia del ejército, de sociología militar y de historia militar propiamente dicha sin atender excesivamente a unas difusas fronteras terminológicas que no afectan esencialmente a nuestros propósitos ${ }^{7}$ - ha ofrecido en las últimas décadas al conocimiento general del período moderno (entiéndase, siglos XVI al XVIII). Nuestra selección de autores, y obras, ceñida sobre todo a la producción europea, se ha guiado por dos criterios fundamentales: el grado de difusión que han tenido en la historiografía española, por un lado, y la influencia que como aportaciones metodológicas al campo de lo militar o de la historia moderna en general han supuesto, por otro lado. Evidentemente, ha tenido más peso el segundo criterio que el primero. Se han preferido también las obras de carácter general a las historias de ejércitos nacionales o de guerras concretas. Finalmente, dedicamos alguna atención a obras que, viniendo de disciplinas afines a la historia han influido mucho en algún aspecto específico de la historia militar.

Fruto de este planteamiento, por méritos propios, será la historiografía británica la que más extensamente nos ocupe ${ }^{8}$, aunque también hemos dedicado espacio a la producción francesa, ya que ambas escuelas puede decirse que son hegemónicas en este terreno en Europa. No obstante, desgraciadamente los intercambios entre las interpretaciones de la guerra en la Edad Moderna de ambas escuelas, mucho más sociológica en Francia y más técnica en el mundo anglosajón, han sido más bien escasos. De hecho, se puede decir que cada una de ellas ha desarrollado debates paralelos con no demasiados elementos comunes. Esta hegemonía se refleja en que, por lo general, los diferentes especialistas europeos se han solido adherir a una u otra forma de abordar lo militar, por lo que nuestro interés se va a centrar en

5 Ver Dosse, F.: La historia en migajas, Valencia, 1988 [1987], «La prehistoria de Annales», pp. 15-56, en especial pp. 31-39.

${ }^{6}$ Existen numerosos compendios bibliográficos sobre la historia militar, algunos de los cuales irán siendo citados a lo largo del texto. Como primera aproximación en castellano, ver el reciente trabajo de Andújar Castillo, F.: Ejércitos y militares en la Europa Moderna, Madrid, 1999; en inglés, destaca, tanto por la calidad en si del contenido como por la variedad de los autores que participaron en su elaboración, la obra dirigida por G. Parker: The Cambridge Illustrated History of Warfare. The Triumph of the West, Cambridge, 1995. En francés, los siglos modernos vienen tratados en el primer volúmen — salvo algunos aspectos referentes al siglo XVIII que se tratan en el segundo volúmen- de otra importante obra colectiva dirigida por A. Corvisier: Histoire militaire de la France, vol. 1, Des origines a 1715, París 1992.

7 Entre los especialistas en historia militar de la Edad Contemporánea, todas estas categorías tienen mucho más sentido. Ver Navajas Zubeldia, C.: «Consideraciones sobre la historia militar», en Hispania, 193 (1996), 739-753.

${ }^{8}$ Es posible que nuestra perspectiva en este sentido esté un poco distorsionada por el hecho de que uno de los autores más influyentes en la historiografía militar británica sea precisamente un renombrado hispanista (Geoffrey Parker). De hecho, aunque es de lamentar el escaso número de obras traducidas al castellano sobre estos temas, la recepción académica en España de los debates europeos sobre aportaciones de la historia militar vienen frecuentemente de la mano de los trabajos de este historiador. Por otro lado, en Estados Unidos la historiografía militar se ha desarrollado aparte de la europea y, dado que su principal campo de estudio era la Edad Contemporánea, la influencia en el terreno que a nosotros nos ocupa aquí ha sido escasa. Ver Barker, T. M.: Army, aristocracy, monarchy: essays on war, society, and gobernment in Austria, 1618-1780, Nueva York, 1982, capítulo 7 (en el que se hace un repaso historiográfico de la producción norteamericana), pp. 147-168; y Borreguero Beltrán, C.: «Nuevas perspectivas para la historia militar: la <New Military History> en Estados Unidos», en Hispania, LIV/1, 186 (1994), pp. 145-177. No obstante, algunos autores norteamericanos que se han ocupado de la historia militar de la Europa moderna aparecerán en este trabajo, como el propio Barker. 
ellas, dejando al margen otras escuelas que, salvo excepciones, han contribuido en menor medida al debate teórico en este campo ${ }^{9}$.

Hacer historia de lo militar, en cualquiera de sus facetas, requiere seguramente del investigador, antes que nada, un concepto más o menos preciso de qué era la guerra en el período histórico escogido para realizar sus investigaciones. Se trata, desde luego, de un concepto cuya aparente evidencia puede conducir a error, ya que tras la obvia respuesta que nos llevaría a contestar que la guerra es el término que define la lucha de dos ejércitos, se esconden múltiples matices. La guerra puede en ocasiones ocultar una represión interna —caso, por ejemplo, de las Guerras de las Alpujarras contra los moriscos-o puede no ser llamada así una confrontación de larga duración en la que el combate directo aún no se ha producido la lucha entre las coronas de Francia y España, iniciada mucho antes de la famosa declaración de guerra de 1635- . Lo cierto es que el uso común de la palabra guerra nos lleva a pensar inmediatamente en la confrontación bélica entre dos países, naciones o estados. Y llegados a este punto, los historiadores modernistas nos encontramos con el primer escollo conceptual: ¿qué término aceptamos para los siglos modernos? ¿Se puede hablar sin más de estados en la Edad Moderna?

Buena parte del debate historiográfico general de las últimas décadas entre los historiadores de los siglos XVI al XVIII ha girado en torno a esta cuestión prioritaria a la hora da abordar casi cualquier análisis de las sociedades de entonces. Ahora bien, si este primordial asunto se puede decir que afectó a la mayor parte de las tradiciones historiográficas europeas, lo cierto es que lo hizo de forma muy diferente. Aquí, vamos a utilizar este argumento como hilo de Ariadna que nos permita adentrarnos en las aportaciones que británicos y franceses han realizado desde esta especialidad para tratar de ir señalando sus aciertos y sus carencias.

\section{LA REVOLUCIÓN MiLITAR}

La aportación de los historiadores británicos de lo militar a este campo ha venido sustancialmente marcada por el concepto que acuñara en la década de los años 50 del pasado siglo Michael Roberts. En una famosa conferencia, Roberts postuló la existencia de una revolución militar que habría tenido lugar a principios de la Edad Moderna en Europa. Según aquella primera teoría sobre la evolución de la guerra moderna, el crecimiento del tamaño de los ejércitos habría requerido cambios de importancia en el funcionamiento de la maquinaria burocrática de los principales estados europeos, siendo así un factor más precisamente en la formación de aquella organización política: el estado. Presentado de una forma tan resumida, el resultado, en cierta forma, deja ver una trampa conceptual, toda vez que lo definido forma parte de la definición. Las transformaciones en la forma de combatir en Europa en las que se detuvo Roberts son aquellas innovaciones que Guillermo de Nassau y Gustavo Adolfo de Suecia sucesivamente introdujeron en la composición y orden de combate de sus ejércitos. Esta aproximación al concepto del cambio en el arte de la guerra, propiciado por los rectores de las entidades políticas, habría supuesto una especie de «revolución desde arriba». La teoría, además, para tener sentido presuponía y necesitaba de un modelo conceptual de estado moderno muy concreto. De hecho, el cambio básico que ambos personajes habrían introducido y perfeccionado en sus ejércitos era de tipo táctico — reducción del tamaño de las unidades e introducción de las formaciones de combate lineales-, lo que sólo dentro de una entidad política homogénea, centralizada y hasta cierto punto burocratizada podría haber sido llevado a cabo. Partiendo de estos cambios, Roberts deducía que en sí mismos habrían llevado aparejados otro tipo de consecuencias de mayor calado en la sociedad: la necesidad

\footnotetext{
9 Es su momento, esas excepciones a las que aludimos tendrán cabida en el texto.
} 
de entrenamiento y preparación, lo que a su vez requería ejércitos permanentes; y el rechazo consecuente de los mercenarios por indisciplinados ${ }^{10}$. A todo ello habría habido que sumar un rápido («sudden») aumento en el número de hombres en combate, sobre todo a partir de las reformas del rey sueco ${ }^{11}$. Una de las primeras consecuencias según la lógica de este planteamiento era la denominación de aparato burocrático (o simplemente burocracia) con la que se abarcaba todo el entramado institucional necesario para poner en marcha los ejércitos ${ }^{12}$, con la enorme carga conceptual que ello implica, que va desde la práctica ausencia de otros centros de poder autónomos asociados a esa forma de administración, hasta la suposición de lo burocrático como un valor objetivado en la sociedad moderna. Aún iba más lejos el autor al afirmar que aquellas transformaciones militares tuvieron un efecto disolvente en el antiguo orden social, al suponer el escalafón militar la aparición de un orden social paralelo que no se basaba en el nacimiento - en referencia a los valores nobiliarios de la época moderna- sino en los valores de la valía personal ${ }^{13}$.

La tesis de Roberts, que ya fue en su tiempo discutida, volvió a centrar los debates conceptuales de gran parte de los historiadores militares — en especial entre los británicos- a partir de la nueva versión que de la misma elaboró en 1988 Geoffrey Parker ${ }^{14}$. Desde entonces $^{15}$, la Revolución Militar ha sido sin duda el principal objeto de discusión de la historiografía militar modernista y acaso el único que ha introducido en el debate verdaderos problemas conceptuales ${ }^{16}$. El gran impulso de Parker, con sus estudios sobre la extensión y perfeccionamiento de las fortalezas defensivas de las ciudades italianas a fines del siglo XV y principios del $\mathrm{XVI}^{17}$, el estilo conocido como trace italiane, tuvo, como primera consecuencia, la vuelta al candelero historiográfico europeo de la historia militar. Aquella versión arquitectónica de la Revolución Militar, amén de rectificar la cronología de Roberts y sustituir la fuerza creadora de los reyes y generales por aspectos técnicos, incluía como elemento esencial del debate la irrupción de la artillería a gran escala en los campos de batalla, los elevados costes y la ralentización de las campañas. Parker defendió que la laboriosidad de los asaltos y la perfección de las defensas hicieron que se llegase a un sistema en el que las maniobras de defensa y ataque «estaban casi exactamente equilibradas» ${ }^{18}$. Esta situación

${ }^{10}$ Roberts, M.: «The military revolution, 1560-1660», [1960] en Rogers: The military Revolution..., op.cit, pp. 1335 .

11 Ibídem, p. 19.

12 Según Roberts, «the transformation in the scale of war led inevitably to an increase in the authority of the state. [...] And the state was concerned to make its military monopoly absolute», Ibídem, p. 20.

13 Ibídem, p. 25.

${ }^{14}$ En 1976 publicó su primera aportación directa al debate con el artículo «La Revolución Militar: ¿un mito?», [en castellano ver España y los Países Bajos, 1559-1659, Madrid, 1986, pp. 115-143] pero fue sobre todo la publicación de su obra La Revolución Militar. Las innovaciones militares y el apogeo de Occidente, 1500-1800, publicada en Cambridge en 1988 [cuya versión en castellano apareció en Barcelona en 1990] la que supuso una significativa aportación. Quizá donde exponga con mayor claridad sus teorías sea en los capítulos elaborados por él en la obra que el mismo dirigió: Parker: The Cambridge Illustrated History of Warfare..., op.cit, en especial capítulo 6, «The gunpowder revolution», pp. 106-120.

15 .R. Hale hizo en 1985 matizaciones puntuales a las tesis de Roberts, antes de que Parker publicase su monografía sobre la Revolución Militar, pero lo cierto es que su crítica al peso concedido a la técnica militar por ser excluyente de otros factores como la moral militar o el patriotismo no es demasiado convincente ni aborda directamente una revisión del propio concepto de Revolución, que ni siquiera menciona. Ver Guerra y sociedad, op.cit, pp. 53-84.

16 Es significativo del abandono en el que se tuvo al concepto mismo de «revolución militar» en las décadas de los 60 y 70 el hecho de que un libro por lo general bastante bien documentado como el de T. M. Barker, publicado en 1982, no mencione tal revolución al hacer su análisis de las aportaciones, entonces recientes, de la historia militar. Ver Army, aristocracy, monarchy..., op.cit, capítulo 7, pp. 147-168.

17 Señala, en concreto, la invasión de Carlos VIII de Francia de la península italiana como el momento decisivo (habla de «divisoria») en el despegue de la extensión del nuevo estilo de fortificaciones, Parker: La Revolución Militar..., op.cit, p. 28.

18 Ibídem, p. 35. 
generaría en el ejercicio de la guerra una tendencia conservadora en el sentido de que, ante la lentitud y dificultad de tomar ciudades defendidas por los modernos sistemas, ciertas monarquías se podían permitir perder batallas sin que luego eso repercutiese en exceso en la firma de la paz, como habría sido el caso sueco tras Nördlingen ${ }^{19}$. Es en este preciso momento de desarrollo de la teoría de la Revolución Militar en el que Parker acepta, matizados por el peso decisivo de las fortalezas, los postulados de Roberts sobre la importancia de los cambios introducidos por Mauricio de Nassau y luego Gustavo Adolfo de Suecia en las formas de hacer la guerra en amplias zonas del continente europeo ${ }^{20}$. En efecto, estos cambios, según la tesis de Parker, sólo con ciertas reticencias y con variedades regionales se fueron imponiendo en la periferia continental (Islas Británicas, Europa del este...). La conclusión de su «revisión de la Revolución Militar» en que acaso el proceso de imposición y extensión de los cambios fue más lento y menos general de lo que en un principio se creyó, por lo que la Revolución vendría a representar una transformación gradual que abarcaría buena parte de la Edad Moderna. Sin embargo, lo que se mantenía era la cronología básica del siglo XVI como el momento en el que los principales cambios se produjeron, quedando las dos centurias siguientes caracterizadas por una simple extensión de tales novedades ${ }^{21}$, al menos hasta el ciclo de las guerras napoleónicas, en las que se habría asistido a otra nueva «revolución militar» ${ }^{22}$.

De esta forma, Parker modificó la tesis original de la Revolución Militar, pero la apuntaló y dotó de nueva vida. Había corregido la cronología e introducido aspectos técnicos desatendidos por Roberts. En cambio, lo que no entró en discusión fue la presunción necesaria de que aquellos cambios eran protagonizados por los estados en sus diferentes formas y que, además, se detectaba una relación directa entre el aumento de los costos de la empresa bélica y el crecimiento de la burocracia estatal. En consecuencia, el advenimiento del absolutismo como forma de expresión máxima del estado moderno quedaba reforzado por esta aportación. Tras este planteamiento, lo que viene actuando desde entonces como telón de fondo del debate es la diferente implicación que se supone al propio objeto de estudio de la historia militar - de la guerra y de los ejércitos- y la influencia que se estimaba tenía todo ello sobre la evolución del conjunto de la sociedad. A partir de aquí es, en nuestra opinión, desde donde mejor se entienden las diversas aportaciones que los especialistas han ido introduciendo en el debate, cada uno de ellos poniendo el énfasis en una gran diversidad de elementos concretos desde los que han buscado el origen de los cambios en la forma de hacer la guerra. Y estos cambios, según una presuposición ampliamente aceptada por ellos, habrían tenido importantes efectos en la organización social y política de la misma sociedad. De hecho, el profesor Parker, a partir del estudio detallado del caso concreto de la logística de la organización militar española en los Países Bajos, pasó a buscar una teoría general de la evolución de los estados europeos desde una perspectiva esencialmente militar, lo que suponía reivindicar un puesto crucial para la disciplina en sí23.

Últimamente, Parker sigue defendiendo su concepto técnico de Revolución Militar, aunque aceptando parte de las objeciones que sus críticos le han ido haciendo. Así, en 1995 aprovechó la ocasión que Rogers le brindó de cerrar el volumen dedicado a repasar las apor-

19 Parker: The Cambridge..., op.cit, pp. 116-117. De modo análogo, esto sería lo que habría hecho poco brillante y carente de acciones decisivas la guerra de los Ochenta Años entre la Monarquía Hispánica y las Provincias Unidas, según dice en su conocido estudio El ejército de Flandes y el Camino Español, 1567-1659. La logística de la victoria y derrota de España en las Guerras de los Países Bajos, Madrid, 1991 [1 $1^{\text {a }}$ edición inglesa, 1972], la cita en p. 15 y más en extenso en Introducción, pp. 37-57.

20 Parker: La Revolución Militar..., op.cit,, pp. 39-47.

21 Ibídem, pp. 23-70.

22 Ibídem, pp. 198-209.

${ }^{23}$ Cierto es que junto al ya citado trabajo de El ejército de Flandes..., Parker ha participado en la elaboración de algunas otras monografías colectivas, como la que dirigió titulada La Guerra de los Treinta Años, Barcelona, 1988 [1984]. Sin embargo, como investigación de fuentes primarias su principal aportación sigue siendo la primera de las referidas. 
taciones al debate sobre el concepto mismo de una Revolución Militar para reafirmar lo esencial de su teoría ${ }^{24}$. Su defensa, en cambio, significativamente sólo atiende, en el apartado que dedica al debate «conceptual», a las cuestiones relativas al término «revolución», por lo que implica de cambio rápido, dedicando muy poca atención a los debates generados por la relación guerra-estado y ninguna a otras cuestiones ${ }^{25}$. Esto no es atribuible tanto a un olvido del profesor Parker, o no sólo, sino a los términos en los que el debate ha sido conducido por los especialistas, más atentos a buscar nuevos elementos decisivos sobre los que defender los cambios revolucionarios que a argumentar sobre el significado mismo de la guerra en la historia moderna ${ }^{26}$.

Significativamente, los primeros historiadores que abordaron y discutieron aspectos concretos de las conclusiones de Parker tuvieron por objeto de estudio el impulso que la guerra habría tenido como «motor del estado», lo que en cierta forma prueba que aquella cuestión fue la que más llamó la atención de la teoría del hispanista británico en un primer momento, al menos entre sus compatriotas ${ }^{27}$. Así, el estudio de B. Downing, en el que expresamente buscaba las raíces remotas de la diversa trayectoria de los países europeos hacia la democracia, atendiendo a su distinta evolución en el siglo XVII, propuso varios modelos de estado en la Europa moderna. Partía de la consideración a priori de que todos los estados europeos, por tradición heredada del medievo, tenían una similar predisposición para evolucionar hacia formas democráticas. Lo que produciría diferencias significativas sería la respuesta ante la presión de la guerra que, se presupone también, sería sustancialmente mayor en aquel siglo que en el anterior. Así, donde la presión de la guerra motivada por el triunfo de la Revolución Militar explotó masivamente y agotó los recursos «nacionales», la tendencia fue a evolucionar hacia el absolutismo; donde se encontraron vías alternativas de financiación o la presión de la guerra fue menor — países en los que, además, tampoco se implantó la Revolución Militar-, las estructuras constitucionales tradicionales pervivieron y facilitaron el tránsito a la democracia en el XIX ${ }^{28}$. En el siglo XVII, por tanto, la cadena causal sería evidente para Downing: una Revolución Militar - que se da por supuesta - obligaría a los estados a invertir más en la guerra, haciendo que en aquellos países en los que los recursos disponibles eran interiores, el gobierno central chocase con las barreras constitucionales que se oponían a su capacidad de extracción fiscal. Para el caso contrario, el autor dejaba la puerta abierta a sus otros modelos de estado, siempre y cuando cumpliesen con uno o más de los siguientes requisitos: ser capaces de mantener una economía fuerte (ejemplos serían Inglaterra y las Provincias Unidas); obtenerlos en el exterior (básicamente las Provincias Unidas, pero también Suecia); mantener alianzas suficientes (las guerras de Francia hasta 1635); o poseer unas características geográficas que facilitasen el aislamiento militar (la insularidad inglesa) ${ }^{29}$. En conclusión, la presión de la guerra habría transformado en algunos países el modelo constitucional al fortalecer desmesuradamente el poder de los reyes, apoyados éstos en una forma burocrático-militar de gobierno ${ }^{30}$. Este ensayo de interpretación macrohistórica, aparte de ciertos olvidos importantes (como el de no tratar el caso de los Austrias madrileños), deja sin explicar — ni siquiera las discute - algunas bases de su argumentación, como

\footnotetext{
24 Parker, G.: «In defense of The Military Revolution» en Rogers: The Military Revolution..., pp. 337-365.

25 Ibídem, pp. 339-341.

26 Parker, G.: ««I end up with the question «why», but I dont start with it»: interview with G. Parker», en Itinerario, 21 (1997), pp. 8-19. En esta entrevista, Parker de nuevo se centró en la defensa de su cronología frente a la opuesta por Downing (vide infra).

27 Estos mismos términos son los que utiliza Andújar Castillo al titular el epígrafe en el que aborda estos trabajos en su estudio historiográfico de la guerra, Ejércitos y militares..., op.cit, p. 25.

28 Downing, B. M.: The military revolution and political change. Origins of democracy and autocracy in early modern Europe, Princeton, 1993, p. 3.

29 Ibídem, pp. 78-81.

30 Ibídem, p. 239.
} 
la propia Revolución Militar o la relación entre la forma de hacer la guerra una sociedad dada y las bases organizativas de la misma. Todo ello es parte y consecuencia de la linealidad evolutiva que sugiere el autor, tan debatida por la epistemología de las ciencias sociales a la altura de la fecha de publicación del ensayo, que le lleva a atender casi en exclusiva a los procesos que se adaptan a esa evolución de largo plazo que él defiende, ignorando o desestimando otros que no encajan con el argumento principal.

Otra versión de la Revolución Militar la ofreció J. Black, quien básicamente se opuso a la cronología de Roberts. Sugería este autor la mayor adecuación de dos períodos de cambio acelerado en la guerra moderna: el primero sería el descrito por Parker; él por su parte se centraba en el período posterior a la Guerra de los Treinta Años (exactamente entre las fechas 1660-1792), en el cual los cambios que él enfatiza habrían transformado la guerra en Europa. Su aportación se estructura sobre la oposición entre los cambios subrayados por Roberts y los que se produjeron sobre todo a principios del XVIII. Ante todo destaca los cambios administrativos, que habrían permitido el desarrollo de los sistemas de recluta y mantenimiento de los ejércitos ${ }^{31}$. Además, Black argumenta que los aspectos sobre los que se fijan tanto Roberts como Parker son sólo meras adaptaciones locales de ideas ya presentes en la teoría militar europea previa. Los que él sugiere, por contra, serían de mayor alcance, al suponer una alteración no sólo técnica (concede mucha trascendencia a la introducción de la bayoneta), sino que implicaría toda una transformación en la forma de hacer la guerra por los europeos $^{32}$. Por tanto, la propia idea de revolución quedaría así rebajada en cuanto a su alcance como alteración sustancial de algo, lo que vendría a sumarse al argumento cronológico que también apuntaría a la improcedencia del uso del término, al tratarse de un proceso secular, discutiblemente «revolucionario ${ }^{33}$. Curiosamente, este autor, pese a reconocer de entrada la existencia de un debate desarrollado en los años ochenta en torno a la naturaleza misma del estado moderno en Europa, se limita en su aportación a rectificar la cronología, manteniendo el problema de la Revolución Militar en sus mismos términos teóricos.

Simon Adams, por su parte, centró sus críticas en un aspecto concreto de la teoría de la Revolución Militar: la cuestión de si se trató esencialmente de una serie de cambios tácticos o si, por el contrario, la raíz de las transformaciones había que encontrarla en el ámbito político $^{34}$. En su aportación al debate, tras poner en duda los resultados de los trabajos centrados en los cambios logísticos — por ejemplo, por la dificultad de arrojar cifras verosímiles sobre el número de los combatientes en una batalla dada o, más aún, en el total de los ejércitos, o por la discutible difusión de las grandes fortalezas construidas según el modelo de trace italiane ${ }^{35}$ - Adams propone un origen «político» en la opción por un tipo u otro de formas de hacer la guerra. Distingue una «escuela española» que se basaría en guerras prolongadas y de desgaste, con predominio de los sitios largos a las principales fortalezas, frente al surgimiento en la Guerra de los Treinta Años de un tipo de combate a campo abierto que buscaba ser decisivo, modelo que sería característico de países con menos reservas o recursos para mantener guerras tan $\operatorname{costosas}^{36}$. Serían dos modos de entender la guerra, uno conservador y defensivo y otro ofensivo y que aspiraba a ser decisivo, representado éste en el ejemplo de las guerras de Maximiliano de Baviera. Adams, frente a la sugerencia de Parker de que los esta-

${ }^{31}$ Black, J.: «A military revolution? A 1660.1792 Perspective», en Rogers: The military revolution..., op.cit, pp. 95-114, p. 98.

32 Aquí nos encontramos con el problema de traducción de los términos «technique»y «technology», cuya traslación al castellano por técnica y tecnología, respectivamente, no nos parece adecuada. Ibídem, pp. 101-103.

33 Ibídem, p. 111.

34 Adams, J.: «Tactics or politics? «The Military Revolution» and the Hapsburg hegemony, 1525-1648», en Rogers: The Military Revolution..., pp. 253-271.

35 Ibídem, pp. 254-257 y 259-260, respectivamente.

36 Ibídem, pp. 263-265. 
dos de la Europa Moderna no encontraron la fórmula de llevar a la victoria a los ejércitos que habían logrado formar, propone que habría que añadir la de que «tras el fracaso de los ejércitos en este período se encuentra el hecho de que se habían depositado en ellos muchas más espectativas de las que podían cumplir» ${ }^{37}$. Así, la principal aportación de Adams es la de incluir una perspectiva política y una voluntad más allá de la imposiciones técnicas en la aplicación o no de determinadas estrategias y novedades logísticas en los ejércitos. En cambio, la propia asunción de los ejércitos como creación estatal remite esta supuesta opción entre modelos diversos a una difusa cabeza rectora que habría optado, desde su absoluta independencia política, por una u otra fórmula. Este planteamiento choca con dos carencias explicativas: ¿las decisiones del mando eran necesariamente seguidas por los generales en campaña? Por otro lado, ¿crea la opción por un tipo de enfrentamiento la ocasión de llevarlo a cabo, sin contar con la posibilidad del enemigo de impedir el planteamiento táctico? La falta de respuesta en la teoría de Adams a la primera cuestión parece apuntar a la desatención de la independencia que, de hecho, tenían buena parte de los jefes de ejército en campañas alejadas de las cortes a las que rendían cuentas. En este sentido, como era de esperar, los propios nombramientos de muchos de estos generales les concedían amplio margen de maniobra e improvisación, toda vez que las distancias y la inseguridad de las comunicaciones impedían el control constante de sus operaciones. La segunda cuestión que señalamos apunta al olvido por el autor de que en las batallas las decisiones en la forma de lucha son dobles y que existe un equilibrio de influencias recíprocas entre los dos ejércitos.

Otro autor que ha investigado la Revolución Militar ha sido D. Eltis, solo que su trabajo ha buscado poner en relación la obra de los teóricos de la guerra durante el siglo XVI con la práctica de la misma ${ }^{38}$. Tras elaborar un examen crítico de los trabajos de Roberts y Parker, centrado sobre todo en la influencia de los elementos técnicos escogidos por ellos para sostener sus respectivas tesis, Eltis afirma, contrariamente a los autores que hemos tratado hasta ahora, considera improcedente remitir automáticamente las transformaciones de las sociedades a los cambios militares por dos razones: primero, porque cualquier gobierno en guerra de cualquier período histórico busca extender su capacidad bélica al máximo de sus posibilidades, lo que supone un rechazo de este pretendido cambio; segundo, porque hacerlo supone desatender la multiplicidad de factores que concurren en procesos de la magnitud del que se trata de explicar desde esta sola perspectiva ${ }^{39}$. Lo que aquí más nos interesa de este trabajo es precisamente esta introducción teórica, por lo que supone de crítica esencial al planteamiento general de la Revolución Militar, aunque no sea intención del autor extender sus argumentos más allá de situar el marco conceptual de su propio trabajo. Por lo demás, el estudio de Eltis es modesto en sus pretensiones teóricas. Básicamente analiza los tiempos y formas en las que las teorías militares continentales fueron penetrando en Inglaterra durante el siglo XVI. Defiende que se produjeron con mucha más lentitud de la que tradicionalmente se estima y con más pervivencias en el uso de armas tradicionales de las esperadas, debido, entre otros factores, a la tendencia conservadora de los teóricos militares ingleses, que alimentaban la desconfianza a los nuevos inventos ${ }^{40}$. De este modo, la idea de cambio realmente innovador o revolucionario queda de plano descartada en Inglaterra.

37 Ibídem, p. 268 [La traducción es nuestra].

38 Eltis, D.: The military Revolution in sixteenth-century Europe, Londres-Nueva York, 1995.

39 Ibídem, p. 32.

40 Widemann, T.: «L'Histoire de l'Histoire de la guerre: l'example de la reference antique», en Revue Historique des Armées, 1997 (2), pp. 3-6. Widemann, analizó los escritos de los teóricos militares franceses en busca de los orígenes clásicos de muchas de sus ideas. En este último estudio, frente a la importancia concedida por los ingleses a los cambios e innovaciones, se prefieren analizar las continuidades. 


\section{MÁs ALLÁ dE LA REVOLUCiÓN MilitaR}

Como vamos viendo, la relación causal guerra-estado pasaba por la pretensión de que la organización de la primera requería el desarrollo de una burocracia - a la que se matizaba con todos los adjetivos referidos al inicio de un proceso que se quieran, desde naciente burocracia a germinal, etc.- - que era entendida como elemento lógicamente imprescindible para hablar del segundo término de la relación. Como se menciona en lo que llevamos dicho, paralelamente al desarrollo de este debate, otras especialidades de la historia discutían las raíces mismas del poder en las sociedades modernas. Así, poco a poco dejó de asumirse como un apriorismo necesario aquel concepto del «estado absolutista» que la historiografía del siglo XIX forjó para oponerle su nuevo y antitético modelo del estado-nación burgués. Este debate general, que permanece abierto en nuestros días, sólo ha comenzado a penetrar con consecuencias visibles en la investigación en el campo de la historia militar modernista en fechas muy recientes y de la mano de historiadores que no tenían como principal argumento de discusión la existencia o no de una revolución militar, aunque sus investigaciones tampoco eludiesen la discusión sobre la existencia de tal revolución. Es probable que la tardanza en la aparición de las huellas de un debate tan importante en la historiografía militar, debate que afecta a la esencia misma de la naturaleza del poder monárquico o central en las sociedades modernas, se haya debido en gran parte a que los sucesivos protagonistas de la revolución militar europea que se han sugerido han sido elementos técnicos del combate o, a lo sumo, tácticos, dejando marginados otros aspectos que tenían que ver con las formas concretas de organización para la guerra. Últimamente, Irvin Thompson o Jonh Lynn han introducido un significativo cambio en el sentido y alcance que se debe dar a esa relación directa, que antes se tendía a ver ineludible, entre el crecimiento de los ejércitos y el consecuente del estado moderno, abocado a ser absolutista bajo aquellos puntos de vista.

La obra de Thompson es quizá el mejor ejemplo de las consecuencias y posibilidades que la apertura de la historia militar a los debates historiográficos más interesantes puede tener, por todo lo que supone de inserción de esta rama de la historia en el conjunto de la interpretación del pasado. Así, mientras su primera gran aportación historiográfica quedaba un poco encorsetada por el marco conceptual en el que aún se movía, sus trabajos posteriores demostraron que, tanto la perspectiva de su estudio como la utilización y selección de fuentes, podían dar frutos aún más sugerentes que los primeros. Partiendo de un planteamiento que fue sin duda en su momento un gran paso adelante en el panorama historiográfico modernista $-\mathrm{y}$ muy en particular en la historia militar-, en el que pretendía valorar la medida del fracaso político de los Austrias hispanos en función de su capacidad para imponer un determinado modelo administrativo, tenido por ellos como ideal, Thompson analizó el funcionamiento de la maquinaria administrativa desarrollada para la guerra ${ }^{41}$. Sin embargo, las posibilidades explicativas que ofrecía la consideración en el tratamiento de las fuentes - básicamente procedentes de las secciones de Estado y Guerra del Archivo General de Simancas-, distinguiendo muy claramente entre lo que tenía esta documentación de reflejo de un ideal y lo que tenía de práctica administrativa, quedaban en alguna medida limitadas por la asunción de una serie de presupuestos tales como la existencia de unas formas de administración burocrática en la etapa previa a las guerras de Carlos V o la aceptación de que esas formas de administración eran propiamente estatales.

En este último sentido, por centrarnos en un ejemplo del tipo de limitaciones que estos presupuestos teóricos imponen, resulta muy ilustrativa la taxonomía que sugiere para distinguir las dos formas antagónicas de administración: la que denomina «administración directa»

41 Thompson, I. A. A.: Guerra y decadencia. Gobierno y administración en la España de los Austrias, 1560-1620, Barcelona, 1981 [1976]. 
— movida por un ideal de servicio «desinteresado»— y el recurso a la administración privada por vía de «asientos» — vistos éstos como participación privada, integración territorial y dejación de funciones estatales-. El paso de la primera forma — que además sería el ideal de la Monarquía - a la segunda - aceptada como mal menor por sus ventajas inmediatas, sobre todo la de ser un sistema más barato- sería el argumento central del libro, con la conclusión de que el proyecto político de los Austrias madrileños habría fracasado al tener que renunciar a su ideal en favor de un sistema perjudicial para los intereses de la propia Corona ${ }^{42}$. En el fondo, se trataría de una decadencia administrativa paralela a la política y militar que habría llevado a una especie de «desvertebración» de España en el siglo XVII. En este caso, la barrera conceptual vendría de la mano de la consideración de ambos modelos como antagónicos, donde el primero sería una burocracia objetivada al servicio del estado, mientras que la segunda sería una especie de «feudalismo administrativo» ${ }^{43}$. Bajo esta dicotomía subyace la división entre las esferas de lo público y lo privado. En nuestra opinión, a la luz de las aportaciones de trabajos posteriores sobre la administración en la Monarquía Hispánica, la división radical entre ambas esferas y entre ambos modelos de práctica administrativa presenta serias limitaciones. Acaso en el fondo no sea adecuado pensar en una verdadera división de fórmulas administrativas opuestas, sino que ante lo que acaso nos encontramos sea más bien ante una diferencia de énfasis en el control, que dependería mucho de la capacidad de extensión de la presencia fiscal del monarca en los diversos territorios. Se trataría, según esta otra perspectiva, de un entramado mucho más complejo en sus motivaciones e intereses, en el que la clave ideológica estaría en la concesión regia y en su posesión por los beneficiados de los cargos - la más o menos estudiada patrimonialización- Tal vez, si aceptamos que la expresión burocracia no se adecua exactamente a la realidad administrativa moderna, lo que podemos inferir es una diferencia de intensidad en la participación de unos poderes locales a través de intermediarios en las empresas de la monarquía, y más aún si atendemos al hecho de que aquellos poderes regionales no dejaron de crecer en el período en el que los intentos de administración directa tuvieron mayor éxito.

El propio Thompson, en trabajos posteriores, ha ido asumiendo parte de las consecuencias del gran debate sobre el estado moderno y matizando sus primeras conclusiones, aunque sin renunciar a la perspectiva de la guerra como elemento administrativo. Esto se percibe bien en algunos trabajos en los que ha criticado los resultados y las principales aseveraciones hechas por los defensores de la idea de la Revolución Militar. Así, en su participación en el debate que Rogers editó hace pocos años, Thompson criticaba uno de los elementos esenciales del planteamiento: el excesivo peso de los lazos entre el estado y la carga financiera que según los teóricos de la Revolución Militar habría supuesto la nueva forma de hacer la guerra, cuestionando desde el porcentaje de la propia participación del gobierno central hasta el alcance de los nuevos costes. En este sentido, señala que el nivel porcentual de gastos, en el caso español, no fue muy superior a principios del siglo XVII que 150 años atrás y, aún admitiendo que había cierto incremento, considera que no queda suficientemente probado que se debiese a la Revolución Militar ${ }^{44}$. Concluye así que los cambios técnicos asociados a la mencionada Revolución no fueron el vector principal del aumento del gasto militar, sino que lo fue el incremento sustancial del número de hombres en armas y su costo. Por tanto, y esto es una aportación sumamente interesante por lo que tiene de apertura del debate al contexto social estudiado, el problema de que en el siglo que media entre 1530 y 1630 el costo de poner un soldado en Flandes fuese mucho mayor se debía principalmente a la inflación mo-

\footnotetext{
42 Ver el último capítulo («Administración y asiento») y las Conclusiones, ibídem, pp. 314-351.

43 Ibídem, p. 315.

44 Thompson, I. A. A.: ««Money, money, and yet more money!» Finance, the fiscal-state, and the military revolution: Spain, 1500-1650», en Rogers: The military Revolution...., pp. 273-298, p. 274-276.
} 
netaria, no al precio del equipamiento ${ }^{45}$. Quedaba por explicar, sin embargo, el aumento del número de hombres al servicio de la Monarquía Hispánica. Para nuestro autor, lo principal fue la inserción de la Península en las guerras europeas de la mano de la dinastía austríaca. Las necesidades generadas por estos gastos — sumados al de las armadas - produjeron como efecto sobre la administración de la Monarquía la búsqueda de fórmulas de repartir el peso del esfuerzo fiscal a nivel local, reduciendo la necesidad de desarrollar el propio aparato administrativo, sobre todo cuando la guerra se produjo en suelo peninsular. En consecuencia, en el caso español, el problema sería que se intentaron las soluciones autoritarias, pero habrían fallado por la crisis de la economía y su ruralización. Así, las guerras interiores aumentaron también la tendencia a reducir el aparato administrativo ${ }^{46}$.

Más recientemente, Thompson ha discutido la teoría general de Downing (vide supra) ${ }^{47}$. En este trabajo señala, en primer lugar, que el olvido del caso español en una teoría general sobre la guerra y el estado europeos en el siglo XVII puede llegar a invalidar sus resultados si la aplicación del modelo no lo corroborase. Comienza su exposición señalando las condiciones hispanas que, en principio, mejor se adaptan al esquema de Downing: sobre todo el aumento vertiginoso del gasto a partir de la Guerra de los Treinta Años (1618-1648) y más aún desde la irrupción de la guerra «doméstica» (1638-1668). Sin embargo, a renglón seguido matiza este incremento al ponerlo en relación con el presupuesto general y los recursos de la Monarquía, equiparando el gasto resultante más o menos al de las décadas de 1570-90. Más novedosa es su profundización en la relación inextricable entre el contexto monetario y el gasto militar, advirtiendo que en el caso español hay que distinguir entre dos tipos de guerras según la especie de moneda en la que se financiasen: guerras interiores pagadas en vellón y guerras exteriores pagadas en plata ${ }^{48}$. Además, aporta más datos sobre la relación entre la inflación del vellón y el aumento nominal del gasto, dado que, cuanto mayor fuese el primero, más crecería el segundo de forma engañosa. Por otra parte, señala los mecanismos concretos con los que los monarcas del siglo XVII fueron sorteando la disparidad entre los ingresos teóricos y las percepciones reales, que básicamente consistieron en la descentralización de los sistemas de pago, llegando a realizarlos en ocasiones en especie ${ }^{49}$. Así, todo este mecanismo, que hacía participar crecientemente a las autoridades locales, denuncia que el sistema tendía a basarse en la «negociación» en lugar de en la «administración». En conclusión, contrariamente a lo defendido por Tilly ${ }^{50}$ y Downing, la presión militar en la Monarquía habría llevado a la Corona a extender su presión «hasta los límites de la arbitrariedad», pero aún así tal coacción se produjo «sin un desarrollo comparable del aparato administrativo estatal, o del poder estatal autónomo» ${ }^{51}$. Su propia sugerencia en este debate es que se debería hacer una distinción entre guerra ofensiva, con fuerte carácter y tendencia centralista, y otra defensiva o «contenida», que sería «conservadora, extensiva, continua y descentralizadora». Por tanto, el ejemplo español muestra que la guerra podía llegar a debilitar al estado o, al menos, no participar en absoluto en su desarrollo ${ }^{52}$.

En estos trabajos, a las propias aportaciones al debate que realiza el autor, hay que destacar también, en nuestra opinión, el cambio conceptual que delatan esas mismas aportaciones y la búsqueda de horizontes interpretativos que suponen. En primer lugar, Thompson ponde-

45 Ibídem, p. 283.

46 Ibídem, pp. 283-291.

47 Thompson, I. A. A.: «La movilización de los recursos nacionales y la tesis de Downing. La guerra y el Estado en España a mediados del siglo XVII», en Martínez Ruiz, E. y Pí Corrales, M. De P. (dirs.): España y Suecia en la época del Barroco (1600-1660), Madrid, 1998, pp. 279-306.

48 Ibídem, p. 285.

49 Ibídem, pp. 288-291.

50 Sobre este autor, vide infra.

51 Thompson: «La movilización...», op.cit, p. 294.

52 Ibídem, p. 304. 
ra la relación entre la guerra y la sociedad y los cauces por los que tal vinculación se produce. Por otra parte, su planteamiento abierto exige la búsqueda de explicaciones en el contexto mucho más amplio de la sociedad moderna, lo que en su caso le lleva a poner en relación los cambios en la guerra con el contexto financiero y monetario. Finalmente, la consideración mucho más difusa de la figura antes hegemónica del estado, ahora matizado por la inclusión clara de otra serie de poderes locales que también jugaban un papel de suma importancia en la guerra, permite situar al propio fenómeno bélico en un contexto social más complejo y rico, merced a la perspectiva adoptada por el autor, que contempla el desarrollo de los preparativos militares desde el inicio del proceso de organización. Junto a la selección de las fuentes, que es otra de las claves renovadoras de los trabajos de Thompson, la mayor aportación del autor es así el nuevo bagaje teórico que sugiere. Al contemplar la administración para la guerra con mayor flexibilidad, el autor sitúa la propia historia militar en un panorama historiográfico más abierto a las aportaciones de otras especialidades. Más allá de la valoración de las conclusiones concretas de Tompson, esta reubicación de la especialidad dentro del modernismo es, en nuestra opinión, muy positiva.

J. A. Lynn, en su reciente y extenso estudio del ejército francés durante el Grand Siècle (1610-1715), aportó un gran número de novedades al panorama historiográfico militar de la Edad Moderna. Partiendo de una perspectiva similar a la que adoptara Thompson en su Guerra y decadencia, al ser su objeto de estudio la organización de toda la maquinaria necesaria para afrontar los cambios de la guerra en la Edad Moderna, aborda el estudio del gigante militar francés en los años en los que él considera que más importantes fueron las novedades militares de la era preindustrial ${ }^{53}$. Según Lynn, el problema que el debate sobre la Revolución Militar ha tenido es que, llevado por historiadores poco interesados por lo militar en sí - al menos en Francia-, el planteamiento de sus trabajos les ha conducido a sacar conclusiones generales antes de conocer los detalles. En concreto, acusa a los protagonistas de este debate - con inclusión ahora de los historiadores anglosajones- de abordar la relación entre guerra y estado sin conocer bien la organización del ejército. En su opinión, la relación entre ambos términos es mucho más compleja de lo que ellos plantean, básicamente por la serie de instancias que intervienen con diferente capacidad de influencia en la formación y control del ejército. Respecto de la Revolución Militar como tal, Lynn rechaza todos los argumentos meramente técnicos, que buscarían una forma de «magia tecnológica» que permitiese explicar las bruscas transformaciones, prefiriendo él abogar por sustituir el concepto «revolución» por un proceso evolutivo basado en transformaciones ideológicas e institucionales ${ }^{54}$.

Su estudio del ejército francés se inicia con una propuesta de evolución general de los ejércitos en la historia europea, desde el año 800 al 2000. El tiempo del que él se ocupó específicamente sería la etapa del «state comision army», que ocuparía un lugar central aproximadamente el siglo XVII - entre los otros dos momentos diferenciados de la Edad Moderna $^{55}$. La caracterización de esta etapa la hace el autor en relación a los otros dos momentos, por cuanto sus notas distintivas serían la consolidación de los ejércitos permanentes, y la progresiva sustitución de los ejércitos bien capacitados técnicamente de mercenarios de la etapa anterior a los menos preparados pero más fiables ejércitos de reclutas, posteriormente dominantes. Se trataría así de una especie de etapa de transición. Cuestión aneja, como cabía esperar, es la de la financiación de este enorme esfuerzo hecho por la monarquía francesa a costa, además, de la necesidad de pedir préstamos a un elevado interés. La diferencia sustancial que marca el estudio de este autor es que, expresamente, sitúa la guerra y lo bélico dentro del estado como un elemento esencial, pero que no aspira a ser decisivo ni autónomo.

\footnotetext{
${ }^{53}$ Lynn, J. A.: Giant of the Grand Siècle..., op.cit, ver nota 1.

54 Ibídem, pp. XIV-XV.

55 Que serían los «aggregate contract army» (siglo XVI) y «popular conscription army» (siglo XVIII), ibídem, pp. 1-64.
} 
De hecho, aunque equipara en importancia al ejército con la propia institución regia, no deja de considerarlo bajo el prisma de su oportunidad y posibilidades políticas del momento. Así, al tratar de explicar el aumento del número de combatientes, Lynn recurre a la demografía, las posibilidades económicas y, sobre todo, alega motivos políticos y estratégicos ${ }^{56}$.

En esta línea, las conclusiones de Lynn son de gran interés al poner en relación su estudio con la Revolución Militar: si bien la mayoría de los autores ha señalado una relación causa-efecto entre crecimiento de los ejércitos y el del estado, en el caso francés, la gran paradoja sería que todo el desarrollo administrativo que comportó la transformación militar no fue capaz de abarcar el tamaño del ejército. La explicación estribaba en la existencia de una serie de instancias intermedias que también ejercían un papel importante en la financiación y control del «gigante francés» ${ }^{57}$. Esta paradoja, según este planteamiento, de un gran crecimiento del ejercito sin un paralelo de la administración del estado, habría sido el que, al cabo de varias décadas, habría llevado al colapso francés de fines del Antiguo Régimen. Lo que sí admite para el caso de Luis XIV es un claro éxito en el control esencial del mando sobre el ejército, del mismo modo que lo hizo sobre su administración. Así, si hay que encontrar el absolutismo en Francia en algún sitio, él sugiere que se haga en este terreno del control político. Aún agrega Lynn que todo ese control se logró sin tener que recurrir a los ejércitos permanentes —que, por lo demás por aquel entonces se empezaron a mantener- para usos de policía o represión interior ${ }^{58}$.

La inclusión de la perspectiva naval en el debate de la Revolución Militar ha sido tardía y ha venido de la mano de un autor no anglosajón, el historiador sueco Jan Glete ${ }^{59}$. Tras la publicación de su monografía en dos volúmenes sobre las marinas de guerra europeas en la Edad Moderna ${ }^{60}$, en la que ya abordaba el tema de la transformación de las estructuras políticas por los cambios bélicos en el mar, resumió y amplió su tesis, estudiando específicamente estas consecuencias en otra monografía más reciente ${ }^{61}$. Glete ofrece en ella una explicación sobre el relativo abandono en que se ha tenido a las marinas dentro del debate en torno a la Revolución Militar. Según él, a los problemas derivados de las fuentes, al menos en comparación con el período posterior a 1650, habría que añadir que los autores que han abordado estos temas lo habrían hecho atendiendo principalmente a las grandes batallas, olvidando el conjunto del desarrollo marítimo ${ }^{62}$. Por otra parte, esta falta de atención también se debería a que los grandes estados invirtieron porcentualmente menos en las marinas de guerra que en los ejércitos de tierra ${ }^{63}$.

En su propia aportación, Glete entiende que la historia de las marinas de guerra europeas hay que contemplarla como una parte específica de la historia de las vías de comunicación marítimas. Esto se traduce en la puesta en relación del desarrollo de las armadas con cinco grandes cuestiones: la formación e integración de estados territoriales; el crecimiento y declive de los imperios ultramarinos; la expansión del comercio por vía marítima y la reestructuración del equilibrio europeo — predominio del norte desde el siglo XVII—; el dominio

56 Ibídem, pp. 60-64.

57 Ibídem, pp. 597-598.

58 Ibídem, pp. 600-609.

59 Es cierto que otros autores habían tratado de los efectos de la introducción masiva de la artillería en los buques de guerra, pero ninguno lo había hecho monográficamente y tratando de poner en relación las transformaciones militares en el mar con las estructuras políticas «estatales» de forma tan ambiciosa como lo hace Glete.

${ }^{60}$ Glete, J.: Navies and nations: Warsihps, navies, and state building in Europe and America, 1500-1860, Estocolmo, 1993.

${ }^{61}$ Glete, J.: Warfare at sea, 1500-1650: maritime conflicts and the transformation of Europe, Londres-Nueva York, 2000. Significativamen, este volumen fue escrito, según relata el propio autor, por invitación expresa del director de la serie, Jeremy Black, uno de los autores sobre la Revolución Militar sobre los que nos hemos ocupado.

62 Ibídem, p. 4.

63 Ibídem, p. 63. 
europeo del mar; y la importancia de los cambios técnicos ${ }^{64}$. La mayoría de estas cuestiones, según él, aún estarían pendientes de respuesta por parte de la historiografía especializada. Respecto a la primera, la referida a la relación entre el estado y las armas marítimas, Glete señala que la mayor parte de los poderes territoriales tuvieron considerablemente menos prisa en monopolizar la iniciativa bélica de sus súbditos en el mar que en la tierra, lo que habría dado una importancia muy especial a ciertos grupos de presión en los estados en los que esto era más evidente ${ }^{65}$. Luego valora la importancia de los grandes centros de actividad marítima en el equilibrio interior de los estados que los dominaban, siendo un factor muy útil en el desarrollo de las marinas de guerra que se produjese una coincidencia de la capital con uno de estos centros, por cuanto suponía un elemento de continuidad en la existencia de fuerzas navales. Sobre estas bases, el proceso que describe Glete entre 1500 y 1650 es de una serie de cambios en Europa con una incidencia muy desigual: mientras que los países mediterráneos perdieron pujanza frente a los nórdicos por su falta de capacidad de adaptación a las novedades, en el norte Europeo se habrían encontrado fórmulas de colaboración entre los comerciantes y las estructuras de poder centrales que habrían desembocado en el control de las principales rutas de comunicación mundiales por esos países ${ }^{66}$. Lo que este convincente cuadro general parece desatender, sin embargo, es el análisis del desarrollo que cabe suponer tendrían esos grupos de presión que negociaban con los poderes estatales, en un proceso durante el cual cabe inferir que también crecerían como consecuencia de esa misma relación. Se echa de esta manera en falta un balance de este crecimiento en paralelo estado-grupos de presión.

\section{OBJECIONES A LA TEORÍA DE LA REVOLUCiÓN MiLITAR}

Como hemos visto, uno de los grandes caballos de batalla del debate de la Revolución Militar es su cronología. Muchos historiadores que han asumido y aceptado el concepto de cambio revolucionario en la forma de hacer la guerra en aquellos siglos han modificado de diversas formas las fechas de la misma. Así, mientras Roberts originalmente sugirió el período dominado por los grandes reformadores que él estudió - Guillermo de Nassau y Gustavo Adolfo de Suecia-, otros autores han sugerido que precisamente aquel período - las últimas décadas del XVI y primeras del XVII- eran las menos significativas en la influencia de los cambios entonces observables, tesis ésta defendida por autores como M.S. Anderson, J. Lynn o J. Black ${ }^{67}$. Además, los historiadores del período medieval han llamado la atención sobre las reformas anteriores al año 1500 que, si bien no completaron el proceso de cambios, sí que se puede afirmar, según ellos, que lo propiciaron y anunciaron ${ }^{68}$. Ante este panorama tan amplio, algunos autores, aunque sin extraer los principales resultados que, en nuestra opinión, de ello se podían derivar, han cuestionado la propia conveniencia del término «revolución» para una serie concatenada de procesos de transformación que abarcarían más de tres siglos — si atendemos a las fechas extremas de los cambios (1400-1750)—. Es probable que no se haya profundizado en las consecuencias de esta cuestión trascendental de nuevo por la

\footnotetext{
64 Ibídem, pp. 1-6.

65 Ibídem, pp. 60-63.

66 Ibídem, pp. 186-187.

${ }^{67}$ En efecto, ya en 1988 Anderson había sugerido que los cambios en los primeros decenios del XVII fueron los más significativos del período, en Guerra y sociedad..., op.cit, p.83.

${ }^{68}$ Esta es la tesis de Mallet a partir de su estudio sobre Venecia en el siglo XV, en Mallet, M. E. y Hale, J. R.: The military organization..., op.cit, p. 4; también ver Ayton, A. y Price, J. L.: «Introducction: the Military Revolution from a medieval perspective», en Ayton, A. y Price, J. L.: The medieval Military Revolution. State, society and early modern Europe, Londrés, 1995, pp. 1-22.
} 
barrera epistemológica que imponían los límites del debate tal y como venía planteándose hasta fechas recientes. Si la Revolución Militar llevaba aparejado un cambio precisamente en algún grado «revolucionario» en la naturaleza administrativa de los «estados», entre tales acción y reacción no debían transcurrir muchos años, so pena de perder su carácter revolucionario. En efecto, si siguiendo esta crítica cronológica llegamos a la conclusión de que se reduce sensiblemente el carácter convulsivo de las transformaciones en la forma de hacer la guerra - es decir, si comprobamos que abarcan un período de más de 75 o 50 años-, resulta mucho más difícil explicar cómo un proceso ahora presentado como esencialmente lento pudo influir decisiva y aisladamente en el desarrollo de los estados europeos. Acaso sea por esta causa que muchos de los autores que han introducido discusiones sobre las fechas límite de la Revolución Militar lo hayan hecho para defender otra cronología alternativa, y no tanto para discutir a fondo el propio concepto ni su influencia sobre la sociedad.

Si la guerra influyó en las formaciones políticas que la sustentaban, llegando a ser un factor decisivo en la aparición del nuevo estado absolutista, ello se debía en muy gran medida al peso creciente en las finanzas que el coste de la guerra tenía, según hemos visto que argumentan muchos de los autores tratados. Ahora bien, si hablar de finanzas tiene sentido en la Edad Moderna se debe, básicamente, a que el contexto económico en el que se desarrolló todo el proceso había sufrido una transformación lenta pero constante en el sentido de que los intercambios mercantiles eran ahora abrumadoramente realizados en moneda. En efecto, la monetarización de la economía europea es un proceso que bajo ningún punto de vista puede quedar marginado de un debate en el que dos de sus componentes sean las finanzas regias - o del gobierno de las repúblicas - y las consecuencias del gasto sobre la propia estructura política que lo soportaba. Sorprende, en cambio, que la historiografía militar, tratando como lo ha hecho de justificar la transformación revolucionaria que supuso la creciente presión bélica, no haya tenido en consideración, al hablar del contexto general de la Baja Edad Media y la Alta Edad Moderna, esta cuestión. En nuestra opinión, este olvido disminuye mucho la capacidad explicativa de todos los argumentos financieros de la Revolución Militar, ya que, si de comparaciones del gasto se habla, es esencial abordar los diferentes contextos monetarios del punto de partida y del de llegada. De hecho, sólo Thompson ha abordado las implicaciones que las formas concretas de pago tenían en el desarrollo real de la administración para la guerra, aunque su punto de vista haya sido el caso concreto de la Monarquía Hispánica y en un tiempo limitado ${ }^{69}$.

Quizá una última cuestión directamente relacionada con el debate de la Revolución Militar, y que probablemente abarca todos los aspectos que hemos abordado hasta el momento, tiene que ver con uno de los principales debates epistemológicos del pasado siglo: la validez de las concepciones lineales que de los procesos históricos forjaran los historiadores liberales del XIX y que tanto ha costado superar a los teóricos del XX. De forma muy sintética, nos estamos refiriendo a la asunción general, por parte de aquella corriente de pensamiento burguesa, de la Historia europea como un movimiento global dotado de sentido y que iba en dirección a una idea muy concreta de progreso, con un comienzo determinado y cuyo fin se podía «prever»o era «anunciado», en ciertos momentos históricos, por algunos acontecimientos o señales. Se trataba de la creencia en que el proceso histórico consta de fases que evolucionan hacia un estadio preciso y necesario, porque tal es el fin natural del mismo. Esta creencia excluía del discurso historiográfico la incertidumbre de las acciones y decisiones abiertas de los hombres en su desenvolvimiento concreto en el tiempo. Impedía ver que la suma de las opciones tomadas por el conjunto de los miembros de una sociedad en una fase dada modifican — $\mathrm{O}$ al menos pueden hacerlo - sustancialmente la fase siguiente y las propias circunstancias coyunturales en las que se toman las decisiones, por lo que un proceso

69 Vide supra, Thompson: «Money, money, and yet more money ...», op. cit. 
dado no puede verse aislado de este cúmulo de incertidumbres estructurales y modificaciones, revolucionarias o no. Como hemos visto, en el caso del planteamiento general de la teoría de la Revolución Militar, los autores que la han defendido partían de la presunción de un momento inicial, caracterizado por la existencia en Europa de una serie de estados débiles, y de otro momento final en el que encontraríamos a los sucesores de aquellas entidades políticas transformadas, merced a las alteraciones en la forma de hacer la guerra, en estados fuertes. La labor que se marcaban, por tanto, estos historiadores era la de descubrir y desentrañar cuáles eran las formas en las que esos cambios decisivos en la guerra se produjeron. En nuestra opinión, esta perspectiva teleológica limita desde el inicio las posibilidades de la investigación histórica, toda vez que el fin queda marcado y la labor del historiador reducida a destacar aquellos elementos modernizadores que se adaptan mejor al marco general trazado.

\section{OTRAS PRESPECTIVAS DE LA HISTORIA MILITAR}

Sobre la influencia de lo militar en el desarrollo del estado, André Corvisier abordó en su momento la cuestión desde el punto de vista de la relación de la sociedad civil con la militar durante la Edad Moderna ${ }^{70}$. Buscó, en primer lugar, situar la percepción de lo bélico $-\mathrm{o}$ aún más genérico, del hecho de la violencia- en la sociedad francesa de aquellos siglos. Según Corvisier, se supone que, al principio del período, se partiría de un momento caracterizado por un deficiente control de los ejércitos por parte de los reyes, por un lado, y por la resignación con la que las poblaciones sufrían sus consecuencias, por otro. La siguiente etapa, de «impregnación militar de la sociedad», se distinguiría por la extensión del uso de las armas entre las capas sociales no privilegiadas, proceso que no hacía sino reforzar una práctica que ya existiría y que distaba mucho del teórico ideal de la división de funciones entre los estamentos. Por otra parte, si bien portar espadas conservó su valor de distinción social, la extensión de la posesión de armas en general sería notable. Todos estos procesos se unirían al factor más importante: la aparición de ejércitos permanentes donde antes se prestaban servicios ocasionales. Este es el momento, a lo largo del siglo XVII, en el que se inicia, según Corvisier, una separación entre la sociedad civil y la militar, proceso que culminaría en el siglo XVIII. En cambio, al abordar la situación en el Siglo de las Luces señala una serie de variantes europeas. Así, mientras en la Europa oriental las sociedades seguían viendo lo militar como un valor incluso moral, en occidente se inició una clara tendencia al rechazo de esos valores ${ }^{71}$. Todo este proceso en los imaginarios colectivos europeos tuvo su plasmación paralela en el desarrollo de las administraciones específicamente dedicadas a la organización de la guerra y en el diferente peso que en ambas zonas tuvo, más desarrolladas e influyentes en oriente que en occidente ${ }^{72}$. A largo plazo, las consecuencias habrían sido que mientras en las sociedades de los países del occidente europeo se habrían acabado imponiendo los valores civiles sobre los militares, en centroeuropa sucedería lo contrario ${ }^{73}$.

De nuevo cabe hacer algunos comentarios a planteamientos como este que acabamos de ver desde la perspectiva de los presupuestos teóricos de la investigación. En primer término, cabe recordar lo que ya queda señalado sobre el estudio de procesos de largo alcance en los que el fin al que se quiere llegar queda prefijado desde el principio mismo de la investigación, por lo que la linealidad del discurso desvirtúa en ocasiones los propios términos del planteamiento. En este caso, además, la peculiaridad de tomar como referente esencial un

\footnotetext{
70 Corvisier, A.: Armées et sociétés en Europe de 1494 à 1789, París, 1976.

71 Ibídem, pp. 11-72.

72 Ibídem, pp. 85-209.

73 Ver también Corvisier, A.: «Guerre et mentalites au XVIIe siècle», en Dix-Septieme Siècle, France, 1985, 37 (3),
} pp. 219-232. 
concepto tan vago y difícil de investigar como pueden ser los sentimientos y emociones colectivas de naciones enteras rebaja mucho la capacidad explicativa del argumento. El relativo mutismo de las fuentes en este sentido es consecuencia, entre otras cosas, de que la abrumadora mayoría de la población fuese analfabeta, por lo que las tentativas de reconstrucción de cualquier aspecto de su universo cultural ha tenido siempre grandes dificultades. Algo similar cabría decir del trabajo de $\mathrm{H}$. Leuwers, quien, al estudiar desde una perspectiva jurídica la influencia de la guerra en la Francia revolucionaria, parte de la repercusión de lo bélico en las mentalidades colectivas. De esta forma, las mentalidades serían a su vez vistas como caldo de cultivo inspirador de los legisladores. Este autor busca así elementos de continuidad en el surgimiento de tales novedades legislativas frente a otras explicaciones más ceñidas al acontecimiento que las habría precipitado ${ }^{74}$.

Otra implicación de suma importancia de la asunción de la relación causal entre crecimiento de los ejércitos y, consecuentemente, del advenimiento del estado absolutista por la historiografía militar tiene que ver con la consideración de la guerra dentro de las funciones del propio estado. En los términos en los que se plantea, se da por supuesto que el estado tiene como función principal la de hacer la guerra, sea esta defensiva u ofensiva. Seguramente ha sido J. L. Price el que ha llevado esta afirmación más lejos en su estudio de las Provincias Unidas en el siglo XVII, en el que afirma categóricamente que la única razón de ser de los organismos centrales de la República era hacer la guerra ${ }^{75}$. Es más, para este autor la propia guerra fue el factor que hizo posible el surgimiento de una identidad común entre las siete provincias rebeldes a la autoridad de los Habsburgo. Así, tras rebatir el tópico del pacifismo holandés, Price afirma que lo cierto es que la estructura militar bátava tuvo la cualidad de no requerir la aparición de una burocracia desarrollada para tener éxito en sus fines ${ }^{76}$. De esta manera, Price admite los términos del debate sobre la Revolución Militar para presentar su objeto de estudio precisamente como excepcional a la regla definida por la propia teoría de la Revolución. Parte de la explicación ofrecida por Price de la originalidad holandesa radicaría en su sistema político, sumamente descentralizado y basado en el pacto de entidades autónomas (las siete provincias). Sin embargo, para compensar esta falta de unidad a la hora de comandar tropas, los holandeses habrían encontrado en la figura del estatúder de Holanda - cargo ostentado por la casa de Orange - la figura «casi monárquica» que precisaban ${ }^{77}$. Así, el sistema holandés sería en el fondo la consecuencia de un pacto defensivo en el que la guerra y las relaciones internacionales serían la partida casi única en la que se invertirían las aportaciones a las escasas instituciones comunes, y ambas cuestiones (la guerra y la acción exterior) quedarían sometidas al estatúder y/o al pensionario de Holanda. Si bien es cierto que el caso holandés es sumamente peculiar, debido a la independencia que de facto tenían los diversos componentes de la República, otra cuestión diferente nos parece la de afirmar que la guerra era el móvil principal del «estado». Para empezar, esto supondría que la guerra era en sí misma un fin y no un medio para obtener réditos o beneficios políticos, económicos, religiosos o de simple prestigio. Esta concepción autónoma de la guerra como fin en sí misma es discutible, incluso en un caso como el holandés, en el que los motivos de la guerra eran tan esenciales como la propia supervivencia como entidad política independiente. En segundo lugar, lo que delata este planteamiento es la consideración que hace el autor del estado como una simple superestructura administrativa situada sobre el entramado territorial

${ }^{74}$ En concreto el autor discute el origen de la supresión del derecho de autogobernearse en la asamblea legislativa de la Francia revolucionaria de finas del XVIII en «Revolution et guerre de conquete: les origines d'une nouvelle raison d'etat (1789-1795)», en Revue du Nord, 1993 (75/299), pp. 21-40.

75 Price, J. L.: «A satate dedicated to war? The Dutch Republic in the Seventeenth Century», en Ayton y Price: The medieval Military Revolution..., pp. 183-200.

76 Ibídem, p. 185.

77 Ibídem, p. 186. 
de provincias controladas, a su vez, por una serie de instituciones locales que hay que suponer no estatales, ya que, si lo fueran, el autor tendría que haber justificado que su dedicación prioritaria era también la de hacer la guerra. Por tanto, esta definición por defecto del concepto de estado vuelve a enfrentarnos con barreras conceptuales de difícil superación.

Otros autores han supuesto también desde perspectivas similares, de forma expresa o no, que la guerra constituía la principal dedicación de los estados. Downing, por ejemplo, necesita esta suposición para elaborar su teoría sobre los cambios de larga duración en las sociedades europeas, como vimos en su momento. Este papel determinante de la guerra en el estado es particularmente necesaria en el caso de los estados que, siembre según Downing, se vieron abocados a desarrollar fórmulas de gobierno absolutistas ${ }^{78}$. De esta forma hay que suponer dos modelos de intensidad en la dedicación bélica, pero el autor no llega a explicar los móviles que empujarían a unos y otros en una u otra dirección. El trabajo de J. Lynn sobre la Francia de Luis XIV, también tiene resonancias de este cierto determinismo militarista, pese a que su planteamiento sea mucho más abierto a la hora de interpretar los vínculos entre la sociedad y la maquinaria bélica que la soportaba y producía (vide supra). Anderson, por su parte, afirma que a principios del XVII es el intento de control del monopolio militar por parte de los gobiernos el principal impulso anunciador del futuro de los estados. Dice textualmente que «la mayoría de los gobiernos de Europa eran, ante todo y en primer lugar, lo mismo que habían sido durante generaciones, máquinas de hacer la guerra»79. En cualquier caso, el problema de explicar los móviles que impulsaban a desarrollar los ejércitos y a comenzar las guerras, que debía implicar una atención especial a las raíces profundas de cómo se gestaban las decisiones sobre la paz y la guerra, sigue intacto en el caso de estos autores citados. Tampoco lo hace Hale quien, sin embargo, se sitúa en el extremo contrario al separar totalmente la guerra de las instancias de poder estatales, presentando el fenómeno como consecuencia exclusiva de las decisiones personales y arbitrarias de los monarcas de turno ${ }^{80}$.

El sociólogo norteamericano Charles Tilly, siempre atento a la elaboración de historias comparadas de los procesos de largo alcance, elaboró hace ya algunos años una versión interpretativa de la evolución de las sociedades europeas en el último milenio, desde el año 990 al $1990^{81}$. En los dos prefacios que anteceden a la versión española del texto, el autor hace una prospección en los orígenes de su propia obra, en los que nos orienta sobre las principales líneas de investigación que centran su interés: la «historia colectiva», los procesos de urbanización y el surgimiento de los estados nacionales ${ }^{82}$. Desde el momento que quedamos advertidos por el propio autor de que su trabajo se va a desenvolver en el nivel de los grandes conceptos y las generalizaciones, el lector sólo puede aceptar o rechazar el planteamiento $\mathrm{y}$, en caso de que lo acepte, sus comentarios deberán moverse en los mismos términos. Se trata, en resumidas cuentas, de un trabajo del género del ensayo histórico, o si se prefiere, de filosofía de la historia - aunque este término goce de muy poco predicamento en nuestros días-. Su teoría de largo alcance parte de unos capítulos en los que sienta las bases conceptuales de su trabajo: definición de estado, del papel que tales instituciones políticas han jugado en la historia y de la relación que han mantenido con las ciudades ${ }^{83}$. Tras dedicar más tarde algunas páginas al proceso de la evolución política europea desde la caída del Imperio Romano hasta el Renacimiento, Tilly analiza los siglos que a nosotros aquí más nos interesan

\footnotetext{
78 Downing: The Military Revolution and political change... Vide supra lo reseñado de la teoría de este autor.

79 Anderson: Guerra y sociedad..., op.cit, p. 18.

${ }^{80}$ Hale: Guerra y sociedad..., op.cit, pp. 30-52. Llega a calificar la potestad de decidir sobre la guerra y la paz de los príncipes de «todopoderosa», pese al crecimiento de la burocracia que entiende aquí como órgano meramente asesor (cita, p. 37).

81 Tilly, Ch.: Coerción, capital y los estados europeos, 990-1990, Madrid, 1992 [Nueva York, 1990].

82 Ibídem, pp. 11-14.

83 Ibídem, pp. 19-69.
} 
diciendo, de entrada, que fueron cruciales en el desarrollo del estado en Europa. Se trata, por tanto, de un momento en el que la evolución histórica de las entidades políticas europeas iniciarían un desarrollo hacia formas más sólidamente estatales, proceso que se vendría a consolidar en los dos siglos siguientes. Significativamente, el capítulo en el que aborda estas cuestiones se presenta bajo el título «De cómo la guerra forjó estados, y viceversa» ${ }^{84}$. Entrando en el contenido, la diferencia sustancial con los otros modelos de explicación macrohistórica que hemos visto hay que buscarla, sin embargo, en los epígrafes que componen el capítulo. Tilly, lejos de basar su teoría en los aspectos técnicos de la guerra, busca dar un enfoque sociológico al problema, capaz de incluir desde aspectos ideológicos o culturales — como la percepción social de la violencia - hasta los más marcadamente administrativos — desarrollo institucional derivado de la tendencia del estado a reservar para sí la exclusividad del uso de la violencia y de la administración creada para sostener tal esfuerzo coercitivo y bélico-. El lugar central que, de todas formas, ocupa la guerra en el análisis de Tilly, le lleva a afirmar que, pese a que la actividad del estado no se reducía a la guerra, las otras actividades básicas eran «productos secundarios de los preparativos para la guerra», entre los que incluye desde los organismos de la hacienda a los tribunales de justicia, pasando por las asambleas públicas o las administraciones regionales ${ }^{85}$.

Este esquema, sin dejar de movernos en sus propios términos conceptuales, presenta algunas dudas. Para empezar, si bien Tilly en su definición de estado sugiere que se debe prestar atención al proceso evolutivo que lleva aparejado para no cometer anacronismos, en cambio, cuando aborda el «período crítico» moderno, utiliza el concepto desde el momento en el que, según él mismo, está empezando su formación. En segundo lugar, la aseveración según la cual el estado buscó conscientemente generar en la población el rechazo a la violencia privada en los siglos modernos queda absolutamente carente de mayor explicación que su propia enunciación, lo cual, dado el lugar central que esta cuestión tiene en el conjunto de su exposición, no deja de ser un obstáculo. Por otra parte, aunque en estrecha relación con lo anterior, si el desarme de la población se hizo por parte del estado entre los siglos XIV y XVII y la aparición de una policía capaz de realizar un control social no se puede datar según Tilly hasta el XIX, lo que queda sin explicar son las formas de control que esos mismos estados nacientes fueron desarrollando en el ínterin, si es que tan levantiscas eran las sociedades modernas como él sugiere. Más aún, esa capacidad represora hubiera sido necesaria a partir de este supuesto, tanto para llevar a cabo el desarme de la población, como para incrementar la presión fiscal. Este último punto aún se complica más en la siguiente conclusión del autor, según la cual en la Edad Moderna se produjo la paradoja de que los ejércitos mercenarios, que son los que habrían dado la fuerza coercitiva necesaria a los estados para hacer las levas, fueron sustituidos por estas nuevas tropas ante el temor que causaban en los gobernantes por su escasa fidelidad.

La valoración moral de la guerra tiene una serie de repercusiones muy ligadas a los conceptos fundamentales que hemos visto dominan en el debate de la especialidad. En general, los autores que se han detenido en este aspecto de la historia militar han solido entrar en este terreno curiosamente para suavizar los efectos negativos que sobre las sociedades tenían los ejércitos o incluso las guerras ${ }^{86}$. Varias líneas se han sugerido para lograr este efecto edulcorante. Una de las primeras, de la que ya hemos tratado ampliamente desde una perspectiva diferente, es la que atribuye un papel central a lo militar en el surgimiento del estado, lo que

${ }^{84}$ Ibídem, pp. 109-148.

${ }^{85}$ Ibídem, p. 120.

86 Anderson puede ser ejemplo de todo lo contrario, al abordar la guerra en el período 1618-1660, al pronunciar un «veredicto» claramente negativo sobre las repercusiones de la guerra en el conjunto de la sociedad. En cambio, en la etapa siguiente, los factores positivos sobre la industria serían ya superiores en un balance general a los negativos, en Guerra y sociedad..., op.cit, p. 77 y pp. 155-156, respectivamente. 
de por sí sería considerado un factor histórico positivo. Este argumento significa darle un contenido filosófico al proceso de formación estatal, lo que supone culminar la perspectiva teleológica con esta guinda valorativa. Otra forma más descarnada de extraer consecuencias positivas es la que lleva a algunos autores a conceder a la guerra una especie de efecto higiénico en los siglos modernos, afirmando que la guerra era el medio del que disponían las capas rectorasde la sociedad para liberar el excedente social improductivo y dañino vagabundos y maleantes - ${ }^{87}$. Por último, una tercera perspectiva ha incidido en las consecuencias sobre el tejido industrial, aunque aquí percibimos fuertes diferencias de planteamiento según los autores — de hecho, no debe confundirse la historia de las industrias militares con juicios más o menos precipitados que utilizan el argumento industrial como mera escusa-. Desde luego, en nuestra opinión, es discutible que sea tarea del historiador extraer consecuencias morales de los procesos que estudia - aunque el ensayo histórico tenga su cabida-, pero sobre todo se pueden cuestionar tales presupuestos cuando esta perspectiva es la que informa el propio planteamiento del trabajo del investigador y la valoración moral del proceso pasa a ser el fin mismo de la investigación.

La historia industrial de la guerra viene ofreciendo desde hace algunos años interesantes aportaciones a la historia general de la industria moderna. En 1965 apareció el trabajo del historiador económico italiano Carlo M. Cipolla, quien se preocupó por indagar, en un famoso ensayo, las causas profundas de la «superioridad» material de la civilización europea en el resto del mundo que se fue manifestando desde la Edad Moderna. Escrito en unos años - los sesenta del siglo XX - en los que la estructura de dominación europea llegaba a sus últimos estertores, en pleno proceso de descolonización, preguntarse por la cuestión de los orígenes de un proceso que concluía era sumamente pertinente ${ }^{88}$. Se trataba, según declaraba el autor en el prólogo, de indagar en cómo el móvil expansivo europeo — digamos, la voluntad de expansión - pudo ser puesto en práctica y en qué medida en los siglos XVI al XVIII, es decir, qué instrumento permitió realizarlo ${ }^{89}$. Como buen historiador de la especialidad, Cipolla iniciaba su estudio en las bases de la economía europea entre los siglos XV y XVI, haciendo un rápido repaso de las estructuras productivas y del tejido comercial en general, pero muy especialmente rastreando la actividad de dos industrias susceptibles de utilización militar: la producción siderúrgica y la fabricación de $\operatorname{barcos}^{90}$. Respecto a la primera, trazó la distribución geográfica de la industria cañonera europea — recordando el consabido proceso de predominio paulatino del norte sobre el sur- y señaló el progresivo incremento del uso del hierro para la fabricación de cañones - lo que sería evidente en los primeros años del siglo XVII y se consolidaría a mediados de aquella centuria-; sobre la segunda destacó la adaptación temprana y exitosa del uso masivo de los cañones en los buques, lo que supondría que las marinas de guerra se habrían adelantado así a la utilización decisiva en las campañas terrestres (salvo en los largos asedios, en los que la movilidad de las piezas era de escasa importancia). Así, trazado el panorama productivo europeo, Cipolla puso este esquema en comparación con lo que sucedía en aquellas tierras que los europeos trataban de dominar en ultramar, midiendo el peso de este desarrollo industrial en la superioridad bélica del Viejo Continente ${ }^{91}$. El resultado difícilmente puede ser más favorable a los europeos. En el epílogo, - el libro no tiene un epígrafe de «conclusión», dado que es evidente para el autor que

\footnotetext{
87 Hale: Guerra y sociedad..., op.cit, p. 32; o Anderson: Guerra y sociedad..., op.cit, p. 30.

88 Nos estamos refiriendo a Guns and sails in the Early Phase of European Expansion, 1400-1700, publicado en 1965. [La edición española que nosotros hemos utilizado es la de Las máquinas del tiempo y de la guerra. Estudios sobre la génesis del capitalismo, Barcelona, 1999, volumen en el que se incluyen dos trabajos diferentes del hstoriador italiano, el segundo de los cuales es traducción del citado Guns and Sails... (Cañones y velas)].

89 Ibídem, p. 93.

90 Ibídem, pp. 95-145.

91 Ibídem, pp. 146-175.
} 
del texto se desprende que la superioridad en el armamento había sido el factor esencial一, recapitula sobre los motivos de los europeos para emprender su expansión. Discutiendo sobre el peso relativo de la religión, resume su opinión perfectamente en la siguiente frase: «la religión facilitó el pretexto y el oro el móvilı ${ }^{92}$. Señala, por lo demás importantes matices, como que la superioridad que en aquellos siglos se logró fue sólo en el mar - habría que esperar al siglo XVIII para que esto se modificase - o que esta superioridad no se puede remitir al conjunto del continente, sino sólo matizando que fue la Europa atlántica la que alcanzó al final del periodo un grado de superioridad tal que le permitió ir desalojando a los poderes mediterráneos de sus antiguas bases ultramarinas ${ }^{93}$.

Hay que destacar aquí la que, en nuestra opinión, es la principal aportación de la historiografía militar española, tanto por la calidad del trabajo, como por la originalidad de las fuentes y perspectiva utilizadas. Nos estamos refiriendo al trabajo del profesor José AlcaláZamora sobre los altos hornos de la España «preindustrial», centrado el ejemplo de Liérganes y La Cavada ${ }^{94}$. Su perspectiva de la Monarquía Hispánica como un proyecto política que buscaba conscientemente su independencia y solidez industrial, aunque tal aspiración resultase a la postre fallida, supone la aplicación y maduración en un caso nacional específico del planteamiento de Cipolla ${ }^{95}$. Esta obra, que desgraciadamente no tuvo las secuelas académicas que merecía en forma de una línea de investigación dotada de cierta continuidad, aparece como un hito aislado en el panorama historiográfico español ${ }^{96}$.

Otros autores han aportado variantes a estos intentos de explicación de por qué un pequeño apéndice del continente euro-asiático extendió su radio de acción bélica a todos los confines del planeta. En Francia, Pierre Chaunu estudió este tema desde el punto de vista de la explotación económica de occidente sobre las otras civilizaciones ${ }^{97}$, mientras Frédéric Mauro planteaba más bien los problemas organizativos de esta expansión en los siglos XVII al XIX, haciendo una especie de arqueología de las estructuras capitalistas desde sus primeros desarrollos hasta la consolidación en la etapa del capitalismo clásico ${ }^{98}$. Parker, quien como vimos dedicó su estudio del desarrollo militar de occidente a la defensa de su propia teoría sobre la Revolución Militar, no dejó de incluir como subtítulo de su obra una referencia al «apogeo militar de occidente». Si bien es cierto que este tema ocupa muy parcialmente la atención del trabajo de Parker. Por lo demás, sus conclusiones son similares a las de Cipolla (vide supra). Todos estos autores, salvo Mauro, hicieron del factor militar o técnico de la imposición política de Europa un factor decisivo, aunque cabe distinguir una diferencia bastante clara entre la corriente francesa y la más técnica de los otros autores. En Francia, donde el estructuralismo marcó la evolución en las ciencias sociales en buena parte de las décadas centrales del siglo XX, y donde, en concreto en el campo de la historia, el modelo de una historia total postulado por Fernand Braudel fijaba un rígido marco cronológico - los famosos tres tiempos de Braudel, desde el tiempo largo de las estructuras al casi anecdótico de los acontecimientos-, la prioridad que se concedía a las explicaciones de base económica es evidente también en este terreno concreto de las explicaciones globales. Algo diferente es el caso del historiador sueco Jan Glete, quien sin abordar directamente la cuestión de historia

92 Ibídem, p. 179. La expresión, no obstante, no es del autor, sino una cita.

93 Ibídem, «Epílogo», pp. 176-187.

94 Alcalá-Zamora y Queipo de Llano, J.: Historia de una empresa española: los altos hornos de Liérganes y La Cavada, 1622-1834, Santander, 1974.

$95 \mathrm{El}$ valor de antecedente que la obra de Cipolla tiene en este trabajo lo reconoce el propio historiador español en «Velas y cañones en la política septentrional de Felipe II» [1973], publicado recientemente en Alcalá-Zamora y Queipo de Llano, J.: Altos hornos y poder naval en la España de la Edad Moderna, Madrid, 1999, pp. 91-124.

96 Desde la historiografía británica, ha sido Hale el que más importancia comparativamente ha dado a las consecuencias sobre la industria del hierro de la demanda militar, Guerra y sociedad..., op.cit, pp. 251-256.

97 Chaunu, P.: Conquista y explotación de los nuevos mundos (siglo XVI), Barcelona, 1984 [1973].

98 Mauro, F.: La expansión europea (1600-1870), Barcelona, 1979 [1968]. 
comparada de porqué se impuso Europa en el mundo, no dejó de hacer notar que la evolución de la marina de guerra occidental fue el elemento clave en la expansión bélica y económica posterior. Para él, lo europeos en Asia se impusieron por el uso de la violencia, ya que poco más que eso podían exportar allí. Por el contrario, su habilidad consistió en que a través del dominio del mar habrían logrado dominar el tráfico de productos asiáticos tanto en el comercio con sus propias metrópolis como en el propio intercambio regional asiático ${ }^{99}$.

\section{LA HISTORIOGRAFÍA MILITAR FRANCESA}

Estas preocupaciones dominantes entre los historiadores franceses, por supuesto, también se dejan sentir en el campo de la historia militar en conjunto ${ }^{100}$. Según J. Lynn, ha sido André Corvisier el que más ha impulsado una reubicación de la historia militar en Francia en las últimas décadas. Sin embargo, este nuevo florecimiento y la renovación de temas que supuso, tuvo su precio. Lynn critica que a causa de esa apertura del campo a historiadores cuya orientación prioritaria rara vez reside en lo estrictamente militar, siendo en la mayor perte de los casos un elemento más o menos incidental ${ }^{101}$. De hecho, la preferencia a afrontar el hecho militar desde una perspectiva preferentemente sociológica - a la que algunos autores llaman, como rama específica de lo militar, sociología del ejército o de las fuerzas armadas- responde a esta misma tendencia general de las ciencias sociales en Francia. Esta circunstancia marca desde el inicio los mismos objetivos con los que en Francia se estudia lo militar ${ }^{102}$. Algunos ejemplos nos podrán servir para ilustrar el tipo de enfoques a los que estamos aludiendo.

En primer lugar, a diferencia de lo que hemos visto predomina entre los anglosajones, los historiadores franceses de lo militar han situado sus estudios del ejército dentro del conjunto de la sociedad. Quizá la apuesta metodológica más innovadora haya sido precisamente la aplicación de métodos tales como las biografías colectivas al campo de lo militar ${ }^{103}$. En segundo lugar, al analizar la procedencia social de los componentes de los ejércitos, el factor humano ha llevado a los franceses a enfrentarse a cuestiones tan variadas como la evolución de la mentalidad colectiva ante el hecho bélico o la aparición de los sistemas de leva forzosa. Finalmente, las repercusiones de la guerra sobre las instituciones políticas y su evolución en los siglos modernos han sido también abordados en relación con las estructuras económicas francesas. Al igual que Carlo Cipolla en Italia, Alcalá-Zamora en España o Parker en Gran Bretaña, Philippe Contamine estudió el peso de la artillería en el desarrollo industrial de la Francia de los siglos XV y XVI ${ }^{104}$. En este caso lo militar se inserta fundamentalmente en el marco legislativo del «estado» y como parte de su iniciativa en esta época.

${ }^{99}$ Glete: Warfare at sea..., op.cit, pp. 68-75.

100 Tampoco se puede decir que abunden las traducciones al castellano de obras de historia militar francesas. De hecho, son aún más escasas que las escritas en inglés. La más conocida y citada por los especialistas españoles es la de R. Quatrefages: Los tercios españoles, Madrid, 1979, en la que se describen básicamente ciertos aspectos técnicos del combate —unidades, desarrollo táctico, armamento-, sin más aparato explicativo. Posteriormente ha publicado otro estudio.

${ }^{101}$ Lynn: Giant of the king..., op.cit, p. XI.

102 Ver Chaignot, J.: «L'histoire militaire de l'epoque moderna (XVIe-XVIIIe siecles)», en Revue Internationale d'Histoire Militaire, 1985 (61), pp. 61-86 [el volumen 61 de esta revista es un monográfico sobre el tema en general de la historia militar en Francia]; Trenard, L.: «Le renouveau de l'histoire militaire», en Information Historique, 1993 (55/3), pp. 98-120.

103 Sobre las limitaciones y nuevas posibilidades de este método ver Durand, R.: «Les biographies colectives en histoire militaire», en Revue historique des Armèes, 1990 (3), pp. 81-90.

${ }^{104}$ Contamine, Ph.: «Les industries de guerre dans la France de la Renaissance: l'exemple de l'artillerie», en Revue Historique, 1984 (271/2), pp. 249-280. 
Esta breve recapitulación sobre la historiografía militar francesa nos permite extraer dos consecuencias fundamentales. Por una parte, que la variedad de los temas que han abordado han acercado más a los especialistas galos a otras ramas o aportaciones de la historia que lo que vimos en el caso inglés, sobre todo después de la aparición de los trabajos de André Corvisier. No obstante, lo cierto es que tampoco en Francia se ha tratado de una especialidad del saber histórico particularmente innovadora, sino que, en todo caso, ha sabido incorporar debates de otras especialidades a su propio bagaje crítico. En segundo lugar, debido a que lo militar ha sido tratado en muchas ocasiones por historiadores formados en otras especialidades, las consecuencias que se han extraído del proceso de transformación durante la Edad Moderna han solido ser formuladas sin conocer suficientemente bien el propio ejército francés, por lo que la relación causa-efecto entre desarrollo de los ejércitos y fortalecimiento estatal adolece, en este caso, de una discutible interpretación del significado del ejército en ese proceso, y no tanto, como sucedía en el mundo anglosajón, por haberle concedido un excesivo peso ${ }^{105}$.

\section{CONCLUSIONES}

En conclusión, según lo que llevamos visto, la historia militar parece haber estado un tanto encorsetada por el marco conceptual que el debate sobre la «revolución militar» —aquí aludimos a los cambios, revolucionarios o no, en la guerra moderna - traía aparejado, sobre todo en el caso de la historiografía anglosajona. Las razones últimas parecen encontrarse en el hecho fundamental de que muchos de estos historiadores de lo militar se han afanado en reivindicar un puesto decisivo para su especialidad en el conjunto de la evolución de las sociedades europeas ${ }^{106}$. Para ello han tendido a presentar el campo de lo militar como una especie de variable independiente que actuaba sobre una Europa que era entendida como un entramado de entidades políticas diversas e inevitablemente confrontadas. Estas entidades políticas eran para ellos necesariamente estatales, toda vez que si la guerra $-\mathrm{o}$ la actividad militar en general - era esa variable que actuaba sobre la sociedad pero de forma un tanto ajena a ella, era precisamente porque los impulsos de los cambios que la propia guerra experimentó en este proceso vinieron fomentados por los reyes o príncipes. Así, el estado o sus representantes eran reconocidos por algunos autores como la única atadura de la guerra como variable social; para otros, al ser los motores del cambio en la forma de hacer la guerra meramente técnicos, la variable se presentaba como casi absolutamente independiente.

Es este peligroso aislamiento en la perspectiva de la historia militar lo que ha impedido a los investigadores de la especialidad que nos ocupa, en nuestra opinión, demostrar aquello que tanto ansiaban: el lugar preeminente de la guerra en la evolución política y social europeas. Seguramente los próximos años vean, una vez superado el debate sobre la Revolución Militar y sus consecuencias, la aparición de numerosos trabajos de historia militar que sitúen a esta especialidad en su justo lugar como variable interdependiente (si se me permite el término) dentro de la historia moderna europea ${ }^{107}$. Para ello las perspectivas múltiples, menos

105 Coincidimos en este caso de nuevo con la crítica hecha por Jonh Lynn en Giant of the king..., op.cit, p. XIV.

106 Caso excepcional en este aspecto concreto es el de J. R. Hale, quien de forma expresiva dice como conclusión de su estudio ya citado que «la guerra condicionó, pero no provocó, los cambios que tuvieron lugar entre 1450 y $1620 »$, en Guerra y sociedad..., op.cit, p. 281.

107 En el último lustro vienen apareciendo en diversos países artículos y publicaciones que abordan los puntos que aquí se han tratado insistiendo en la necesidad de renovación y otros poniéndolo en práctica. Así, por ejemplo, Bernd, O.: «<Militärgeschichte von unten>: anmerkungen zu ihren ursprügen, quellen und perspektiren im 20. Jahrhudert», en Geschichte und Gesellschaft, 22 (1996), pp. 473-503, en el que defiende la tradición alemana de una historia social de los ejércitos y de la necesidad de hacer planteamientos complejos en los estudios y de someter a crítica a las fuentes; de Vries, K.: «Catapults are not atomic bombs: towards a redefinition of «efectiveness» in premodern military technology», 
encasilladas en los límites de las ramas historiográficas clásicas y, por tanto, capaces de atender a los fenómenos sociales desde todas las perspectivas del poder en sus diversos estratos sociales (como ya viene sucediendo), auguran la proliferación de horizontes y objetos de estudio históricos nuevos en los próximos años, algunos ya indicados.

Luis SALAS ALMELA

en War in History, 4 (1997-4), pp. 454-470, en el que se postula la sustitución del término revolucionario para los cambios en la técnica militar por el de «evolucionarios»; Lynn, J.: «The embattled future of academic Military History», en Journal of Military History, 61 (1997), pp. 777-7789. Muy interesante es también el trabajo de S. Reid: All the King's Armies. A Military History of the English Civil War, 1642-1651, Staplahurst, 1998; 